\title{
USE OF COPEPTIN IN DIFFERENTIAL DIAGNOSIS OF (ACS) FOR MALES VS FEMALES IN EMERGENCY DEPARTMEN
}

\author{
Hossam A. Shahin ${ }^{1}$, Sabah F. El Abd², Emad F. Abdel Maksoud ${ }^{3}$, Wael S. Abdel Mageed²
}

${ }^{1}$ Ass. Professor of cardiology, Vice Dean, National Heart Institute, Imbaba, Giza, Egypt.

2Molecular Biology Department. Genetic Engineering and Biotechnology Research Institute (GEBRI), Sadat University, Sadat City, Minufiya, Egypt.

${ }^{3}$ Specialist of Biochemistry, Laboratory department, National Heart Institute, Imbaba, Giza, Egypt.

\begin{abstract}
Difference between men and women in the treatment and outcome of acute coronary syndromes has been demonstrated with increased deaths rates in women. Treatment of ACS must be revised and related to the sex and race of the patient. The aim of this study was to introduce new copeptin cutoff levels in ACS patients depending of gender. Also, to compare copeptin to hs-cTnl, CRP levels to predict time delayed between ACS symptoms onset and admission to ED. Sixty two consecutive patients with ACS presenting to the emergency department of the National Heart Institute, Giza (Egypt) between March and June 2014, were recruited for the study. The present study involved thirty patients with unstable angina (19 male \& 11 females), thirty two Ml patients (18 males \& 14 females) and twenty healthy subjects (10 males \&10 females) on admission and after 6 hours. Results revealed significant difference between cardiac levels on admission with higher values in men on admission only for CPP, disappeared after six hours. Only copeptin levels were diagnosing on admission (higher with clear cut off levels either for men or women) compared to that of six hours (decreased and get non-significant differences). Early measurement of the combination of troponin I and copeptin may revolutionize the diagnostic accuracy and therapeutic decision-making in patients with symptoms suggestive of ACS, differentiate between UA or AMI patients on admission. Female patients require reevaluation criteria for treatment and outcome.
\end{abstract}

Key words: ACS in males vs. females, Copeptin, AMI, UA, cTnl, hsCRP, cardiac markers.

\section{INTRODUCTION}

Although the great progress in diagnosing, treating and judgment of acute coronary syndrome (ACS) patients, it is still the main cause of mortality and morbidity all over the world. According to AHA (American heart association), ACS include unstable angina (UA), non-elevated ST myocardial infarction (NSTEMI) and ST elevation myocardial infarction (STEMI) patients (Libby 2001).

It was noticed that there is a great difference between men and women in the treatment and outcome of acute coronary syndromes with an increased deaths rates in women. This is due to that women with suspected acute coronary syndrome are less likely to have a proper diagnosis since observation attributed to atypical symptoms and less reliable findings on electrocardiography are misleading criteria (Shah et al., 2015).

In spite of increasing sensitivity of troponin assays with recent varied cut off to males versus females (men $34 \mathrm{ng} / \mathrm{L}$, women $16 \mathrm{ng} / \mathrm{L}$ ), there is still some ACS cases can't be diagnosed for assured levels (> 50 ng/L) (Keller et al., 2009). UA patients can be presented without any objective data of myocardial ischemic injury (normal ECG and normal troponin). Hence diagnosis depends only on the patient's clinical history and the clinician's interpretation and judgment. In such conditions, patients must be evaluated rapidly either through serial ECGs or troponin assays. This is time consuming and patients may develop serious symptoms which are life threaten (Duchenne et al. 2014).

Recently, treatment of ACS are related to the sex and race of the patient since previous studies in the last two decades reported differences in treatment according to sex and race. Moreover, in the past decade, more investigations demonstrated less intensive treatment of acute myocardial infarction in women, as compared with men, although sex and racial differences in the treatment of ACS have been demonstrated for more than a decade, knowledge is little about whether these differences have persisted up till now (Vaccarino et al., 2005).

Arginine vasopressin (AVP), or antidiuretic hormone (ADH), is secreted in response to acute diseases due to haemodynamic changes. The Cterminal peptide of provasopressin (copeptin) is released in equimolar amounts to AVP and is easy to determine. Recently, copeptin became a novel biomarker for ACS either for diagnosis or rule out marker. Many studies reported copeptin when combined with cardiac troponins in diagnosis of patients presenting with acute chest pain in early hours accelerates early rule in of AMI 
or rule out of non-MI patients (Gimenez et al., 2014).

Many studies found that copeptin exhibits a rapid increase in plasma immediately after the onset of chest pain, then declines after 4-6 hours due to invivo degradation. So, its value is highly obvious within the early 4 hours from chest pain onset, particularly for NSTEMI patients with negative cTns on admission to ED (Walter et al., 2015). There is still an important question about copeptin diagnosing cut off levels for males vs. females.

There are very rare studies considered copeptin for differential diagnosis of ACS. Copeptin can be measured in all ACS patients since it is the main response of stress accompanying pain in such patients (Reinstadler et al., 2015). The aim of this study was to investigate copeptin levels in ACS patients (males vs. females) and compare them to cardiac troponin I, c-reactive proteins, total creatine kinase (CK) and CK-MB sub-fraction plasma levels in unstable angina (UA), acute myocardial infarction (AMI) and control subjects for the differential diagnosis of ACS in chest pain patients presented to the ED on admission and after six hours from admission using sex specific diagnostic thresholds.

\section{SUBJECTS AND METHODS \\ Patients:}

A total of sixty two consecutive patients with chest pain or other symptoms suggestive of ACS presenting to the emergency department of the National Heart Institute, Giza (Egypt) between March and June 2014, were initially recruited for the study. They were grouped as male or female patients. Patients with hepatic or renal disease were excluded. All patients included in the study gave their written informed consent. Patients are grouped into two groups according to the final diagnosis as AMI (including thirty two patients) and UA (including thirty patients) groups. Another control healthy group consists of twenty subjects were included also in this study. All groups were sub grouped depending on gender as unstable angina (19 male \& 11 females), Ml patients (18 males \& 14 females) and healthy subjects (10 males \&10 females).

\section{Study Protocol:}

On admission, all patients underwent an initial clinical assessment, including medical history, temperature, blood pressure, pulse and ECG. Risk factors and medical history were collected as stated by the patients, and also the treatment received. ECG was performed after 2, 4, 6 and 12 h.

\section{Blood Sampling:}

Samples from control and patients were drawn in dry, clean, ion-free tubes, left to be clotted and centrifuged. The separated sera were divided into 2 parts. One of them was kept at $-20{ }^{\circ} \mathrm{C}$ till used for measuring of CPP, cardiac Troponin I (cTnl) and CRP. The other serum samples were estimated immediately to minimize the errors due to the light and heat effects on their enzyme activities. They were studied for activities of total creatine kinase and its CK-MB isoenzyme and lactate dehydrogenase activities to assess the incidence of acute myocardial infarction.

The clinical investigations were assessed by serum estimation of alanine transaminase (ALT) activity, levels of plasma urea and blood sugar.

Laboratory assessment of acute myocardial infarction were defined in patients whom serum enzymes activities and cardiac protein markers were significantly higher than the upper limits of the control subjects and the upper limits assessed previously by the kits used for the assays.

\section{Laboratory investigations}

All myocardial markers, were analyzed by using a commercial kits according to the manufacturer's instructions. Mmeasurement of the biomarker copeptin was assayed by kits provided by (BRAHMS AG, Henningsdorf, Germany), a cutoff value of $<14 \mathrm{pmol} / \mathrm{L}$ was specified for rapid exclusion of acute $\mathrm{MI}$, as recommended by the manufacturer.

\section{Statistical analysis:}

An IBM compatible PC was used to store and analyze the data and to produce graphic presentation of important results. Calculations were done by means of statistical software packages namely (SPSS, version 17).

Data were tabulated and statistically analyzed to evaluate the difference between the whole groups under investigations as regards the various parameters. Together, correlation was tried in between the essential studied parameters. The statistical analysis included the arithmetic mean value, standard deviation, and hypothesis student "t" test and the significance of result $(P)$.

\section{RESULTS AND DISUCSSON}

Table (1) represents results of the anthropometric measurements for all investigated groups (male vs. females). There were significant variations in height and BMI in control and UA subjects but not in AMI patients. Although there were numerical (higher) ages in both UA and AMI groups for females but they weren't significant BMI. Investigating clinical markers of liver, kidneys and glucose revealed no differences in renal or hepatic functions between males compared to females where they found to be in the normal levels. Glucose was found to be high in the AMI group regardless gender denoting high risk for ACS events in diabetic patients (Table 2). Cardiac markers for control subjects group were considered as the reference values for all groups (Table 3). In UA group, there were significant difference in the cardiac markers, LDH, CRP and 
(Table 1) Anthropometric data for males compared to females

\begin{tabular}{|c|c|c|c|c|c|}
\hline \multicolumn{6}{|c|}{ Control (Mean \pm SD) } \\
\hline & Male $(\mathrm{N}=10)$ & Female $(\mathrm{N}=10)$ & $\mathrm{t}$ & $p$ & Significance \\
\hline Age (Years) & $55 \pm 6.63$ & $57 \pm 5.93$ & -.852 & .416 & NS \\
\hline Height (m) & $1.75 \pm 0.06$ & $1.66 \pm 0.06$ & 3.564 & .006 & $\mathrm{~s}$ \\
\hline Weight (kg) & $82.9 \pm 6.59$ & $87.3 \pm 7.24$ & -1.412 & .192 & NS \\
\hline $\mathrm{BMI}\left(\mathrm{kg} / \mathrm{m}^{2}\right)$ & $26.90 \pm 2$ & $31.49 \pm 2.01$ & -4.960 & .001 & $\mathrm{~S}$ \\
\hline \multicolumn{6}{|c|}{ UA (Mean \pm SD) } \\
\hline & Male $(\mathrm{N}=19)$ & Female $(\mathrm{N}=11)$ & $\mathrm{t}$ & $p$ & Significance \\
\hline age & $58.84 \pm 5.65$ & $61.36 \pm 5.77$ & -.612 & .554 & NS \\
\hline height & $1.745 \pm 0.05$ & $1.66 \pm 0.05$ & 3.445 & .006 & S \\
\hline weight & $87.05 \pm 10.42$ & $90.90 \pm 13.54$ & -.027 & .979 & NS \\
\hline BMI & $28.55 \pm 2.81$ & $33.05 \pm 5.49$ & -1.555 & .151 & NS \\
\hline \multicolumn{6}{|c|}{ AMI (Mean \pm SD) } \\
\hline & Male $(\mathrm{N}=18)$ & Female $(\mathrm{N}=14)$ & $\mathrm{t}$ & $p$ & Significance \\
\hline age & $57.88 \pm 6.96$ & $59.28 \pm 5.18$ & -.293 & .774 & NS \\
\hline height & $1.72 \pm 0.07$ & $1.67 \pm 0.07$ & 1.636 & .126 & NS \\
\hline weight & $88.22 \pm 11.78$ & $87.92 \pm 13.84$ & -.463 & .651 & NS \\
\hline BMI & $29.86 \pm 3.94$ & $31.50 \pm 5.2$ & -1.472 & .165 & NS \\
\hline
\end{tabular}

UA Unstable angina

AMI Acute myocardial infarction

BMI Body mass index

(Table 2) Clinical data for males compared to females

\begin{tabular}{lccccc}
\hline \multicolumn{7}{c}{ Control (Mean \pm SD) } \\
\hline MLT (U/l) & $25.3 \pm 5.14$ & $24.8 \pm 4.96$ & .267 & .796 & Significance \\
GLU(mg/dl) & $88.4 \pm 7.72$ & $87.3 \pm 10.4$ & .249 & .809 & NS \\
Urea(mg/dl) & $27.7 \pm 7.63$ & $24.5 \pm 5.74$ & 1.288 & .230 & NS \\
\hline \hline \multicolumn{7}{c}{ UA (Mean \pm SD) } \\
\hline ALT & Male (N=19) & Female (N=11) & $t$ & $\mathrm{p}$ & Significance \\
GLU & $28.73 \pm 5.03$ & $25.90 \pm 3.91$ & .589 & .569 & NS \\
Urea & $93.05 \pm 9.57$ & $92.90 \pm 13.35$ & .298 & .772 & NS \\
\hline \hline
\end{tabular}

AMI (Mean \pm SD)

\begin{tabular}{lccccc}
\hline & Male $\mathbf{( N = 1 8 )}$ & Female $(\mathbf{N}=\mathbf{1 4})$ & $\mathrm{t}$ & $\mathrm{p}$ & Significance \\
\hline ALT & $25.05 \pm 4.84$ & $26.92 \pm 3.63$ & -.888 & .391 & NS \\
GLU & $138.27 \pm 78.4$ & $121.92 \pm 63.19$ & .462 & .652 & NS \\
Urea & $28.33 \pm 5.93$ & $34.71 \pm 8.59$ & -1.992 & .068 & NS \\
\hline \hline
\end{tabular}


(Table 3) Cardiac markers for males compared to females

\begin{tabular}{|c|c|c|c|c|c|}
\hline \multicolumn{6}{|c|}{ Control (Mean \pm SD) } \\
\hline & Male $(\mathrm{N}=10)$ & Female $(\mathrm{N}=10)$ & $\mathrm{t}$ & $p$ & Significance \\
\hline $\mathrm{CK}(\mathrm{U} / \mathrm{l})$ & $60 \pm 16.9$ & $61.8 \pm 11.32$ & -.244 & .812 & NS \\
\hline CKMB(U/I) & $5.5 \pm 1.08$ & $5 \pm 0.94$ & 1.000 & .343 & NS \\
\hline $\mathrm{LDH}(\mathrm{U} / \mathrm{l})$ & $230 \pm 45.24$ & $220.7 \pm 50.83$ & .597 & .565 & NS \\
\hline CRP(ug/ml) & $3.86 \pm 3.1$ & $5.11 \pm 4.07$ & -.766 & .463 & NS \\
\hline TROP I(pg/ml) & $8.1 \pm 2.73$ & $9.9 \pm 3.98$ & -1.197 & .262 & NS \\
\hline \multirow[t]{3}{*}{$\mathrm{CPP}(\mathrm{pg} / \mathrm{ml})$} & $7.62 \pm 2.27$ & $9.97 \pm 2.25$ & -2.040 & .072 & NS \\
\hline & \multicolumn{2}{|c|}{ UA (Mean \pm SD) } & \multicolumn{3}{|c|}{ Admission } \\
\hline & Male $(\mathrm{N}=19)$ & Female $(\mathrm{N}=11)$ & $\mathrm{t}$ & $p$ & Significance \\
\hline CK & $107.89 \pm 41.6$ & $96.89 \pm 25.37$ & 1.247 & .228 & NS \\
\hline CKMB & $8.63 \pm 3.95$ & $8.36 \pm 3.62$ & .418 & .681 & NS \\
\hline LDH & $353.10 \pm 75.18$ & $302.10 \pm 57.86$ & 3.260 & .004 & $S$ \\
\hline CRP & $14.18 \pm 7.45$ & $18.48 \pm 8.3$ & -3.425 & .003 & S \\
\hline TROP I & $11.57 \pm 3.91$ & $12.31 \pm 3.82$ & -.801 & .434 & NS \\
\hline \multirow[t]{3}{*}{ CPP } & $11.83 \pm 5.15$ & $8.33 \pm 3.28$ & 2.459 & .034 & $\mathrm{~S}$ \\
\hline & \multicolumn{2}{|c|}{ UA (Mean \pm SD) } & \multicolumn{3}{|c|}{ After 6 hrs. } \\
\hline & Male $(\mathrm{N}=19)$ & Female $(\mathrm{N}=11)$ & $\mathrm{t}$ & $\mathrm{p}$ & Significance \\
\hline CK & $69.72 \pm 27.94$ & $85.90 \pm 31.08$ & -1.490 & .167 & NS \\
\hline CKMB & $6.54 \pm 2.3$ & $8.45 \pm 2.73$ & -2.524 & .030 & $S$ \\
\hline LDH & $263.81 \pm 49.47$ & $273.90 \pm 58.15$ & -.454 & .659 & NS \\
\hline CRP & $15.74 \pm 6.66$ & $24.99 \pm 27.6$ & -1.140 & .281 & NS \\
\hline TROP I & $9.90 \pm 3.81$ & $12.27 \pm 2.41$ & -1.662 & .128 & NS \\
\hline \multirow[t]{3}{*}{ CPP } & $9.80 \pm 3.67$ & $9.4 \pm 3.01$ & .564 & .580 & NS \\
\hline & \multicolumn{2}{|c|}{ AMI (Mean \pm SD) } & \multicolumn{3}{|c|}{ Admission } \\
\hline & Male $(\mathrm{N}=18)$ & Female $(\mathrm{N}=14)$ & $t$ & $p$ & Significance \\
\hline CK & $247.22 \pm 161.58$ & $154.28 \pm 90.02$ & 2.480 & .028 & $S$ \\
\hline CKMB & $29.22 \pm 17.22$ & $19.57 \pm 13.52$ & 1.964 & .071 & NS \\
\hline LDH & $352.83 \pm 101.95$ & $390.28 \pm 119.82$ & -.413 & .686 & NS \\
\hline CRP & $24.97 \pm 12.81$ & $24.33 \pm 14.88$ & .133 & .896 & NS \\
\hline TROP I & $86.33 \pm 100.52$ & $113.5 \pm 261.54$ & -.315 & .758 & NS \\
\hline \multirow[t]{3}{*}{ CPP } & $28.54 \pm 14.91$ & $22.75 \pm 10.45$ & 2.970 & .023 & $\mathrm{~s}$ \\
\hline & \multicolumn{2}{|c|}{ AMI (Mean \pm SD) } & \multicolumn{3}{|c|}{ After 6 hrs. } \\
\hline & Male $(\mathrm{N}=18)$ & Female $(\mathrm{N}=14)$ & $\mathrm{t}$ & $\mathrm{p}$ & Significance \\
\hline CK & $660.94 \pm 186.91$ & $553.92 \pm 210.1$ & 1.376 & .192 & NS \\
\hline CKMB & $61.5 \pm 10.33$ & $63.71 \pm 18.16$ & -1.024 & .325 & NS \\
\hline LDH & $773.27 \pm 182.32$ & $894.5 \pm 282.06$ & -1.768 & .101 & NS \\
\hline CRP & $59.98 \pm 29.79$ & $49.88 \pm 28.96$ & 1.277 & .224 & NS \\
\hline TROP I & $163.16 \pm 128.01$ & $171.21 \pm 226.91$ & .091 & .929 & NS \\
\hline CPP & $15.09 \pm 6.26$ & $15.31 \pm 6.39$ & -.115 & .910 & NS \\
\hline
\end{tabular}


copeptin demonstrated in the admission measured samples which were disappeared after 6 hrs. Only CK-MB levels were found to be significantly higher in the second samples (after 6 hrs.) indicating minor heart necrosis although they were still in the normal reference ranges. Hence, there is a cardiac muscle leakage associated with angina leading to increased CK-MB or there is a muscle mass difference. Also, haemodynamic changes due to UA symptoms on admission leading to increased CPP were returned in the second samples, decreased significantly, indicating stability of patients' cardiac out put. This notice was found in AMI patients too where CPP levels were found to be higher in males on admission and returned to be equal after $6 \mathrm{hrs}$.

All markers were found to be elevated after six hours from admission for AMI patients except CPP which was acutely decreased indicating no effectiveness in diagnosing $\mathrm{AMI}$ in the second samples. CPP was only highly indicative on admission and may assure Ml within few minutes to hours after symptoms onset.

Regarding cardiac markers for three groups on admission, AMI markers were found to be highly elevated compared to that obtained in the two other groups (Control \& angina) including CPP. Copeptin levels were significantly differed between the three groups with varied range for each group regarding type of ACS versus control subjects.

Regarding diagnostic accuracy, CPP was found to be higher in men than women, more than the cut off value (> $12 \mathrm{pg} / \mathrm{ml}$ ) in AMl patients group on admission and was found to be $(28.54 \pm 14.91$ for males \& $22.75 \pm 10.45$ for females). Hence, CPP is highly significant differential diagnosing marker on admission to ED for ACS syndromes but not after six hours.

The diagnosis of acute coronary syndromes has become increasingly dependent on serum markers of cardiac injury. Subjects were studied for activities of total creatine kinase and its CK-MB isoenzyme, lactate dehydrogenase, high sensitive cardiac troponin I (hs-cTnl) and copeptin (CPP) levels to assess the rule out of acute myocardial infarction on admission or MI developing after 6 hours. Indeed, patients with acute coronary syndromes demonstrate elevated serum levels of C-reactive protein (CRP), indicative of a systemic inflammatory response (Libby et al., 2008).

In this study, the serum inflammatory marker, the acute phase reactant protein CRP levels were estimated (by a high sensitive method) for ACS patients on admission, after 6 hours. Results differences were not significant between women and men in anginal or Ml on admission, after $6 \mathrm{hrs}$. These findings suggest that inflammatory immune activation in coronary arteries initiates acute coronary syndromes, with equal -in both men and women- circulating levels of inflammatory markers reflecting the clinical course of the condition. Hanson (Hanson 2005) and Luizzo et al. (Liuzzo et al., 1998) postulated that levels of C-reactive protein are elevated in patients with unstable angina, a condition that is probably dependent on coronary thrombosis of atherosclerotic plaques, but not in those with variant angina caused by vasospasm. Therefore, elevated C-reactive protein levels in patients with acute coronary syndromes likely reflect inflammation in the coronary artery rather than in the ischemic myocardium. Results of several studies show a strong link between baseline elevations of CRP and the risk of future cardiac events (Ridker 2009). The current study was proposed to assess levels of copeptin in relation (hs-cTnl) in a group of patients with ACS (either UA or MI) and to compare these levels to sex (Males vs. females). Patients with ACS from the emergency department are one of the most difficult challenges that face emergency physicians today. The present study involved thirty patients with unstable angina (19 male \& 11 females), thirty two MI patients (18 males \& 14 females) and twenty healthy subjects (10 males $\& 10$ females).

Previous studies of sex-based differences in acute coronary syndromes (ACS) have revealed conflicting results although both men and women have comparable symptoms of chest pain other than concomitant vaso-vegetative symptoms in women that can mask the chest pain. Also, women have less extensive ST-T elevations at admission especially at younger ages which may lead to misdiagnosing at the emergency department (Berger 2009).

Cardiac markers results of the current study compromised three amazing results as non significant elevation on admission (high results but in the gray zone bands), significantly differed results of second results after $6 \mathrm{hrs}$. except for CPP compared to that obtained at admission and the very wide standard deviations in all markers. CPP had diagnostic results on admission diagnosing UA or AMI but not after $6 \mathrm{hrs}$.

Globular cardiac markers including enzymes (CK, CK-MB \& LDH) are distributed in the cardiac cells' cytoplasm can escaped even at hypoxia without true cellular lyses. Moreover, muscle mass in females are much lower than men (Dhakad and Sharma 2015).

Of course cTnl levels in AMI patients -males and females- were higher than that of the cut off levels either in the admission samples or after the $6 \mathrm{hrs}$., but also the SD levels were widely varied due to the wide variation of results which may reach 50 times the base line values (up to $20 \mathrm{pg} / \mathrm{ml}$ ). Although there are many studies found cTnl levels under the cut off values, it was found to be very high in this study. This may be due to late arrival 
to the ED. The two components of the acute coronary syndromes (ACS), acute myocardial infarction (AMI) and unstable angina (UA) are major causes of death and disability worldwide. The risk of death and the benefit from early revascularization are highest within the first hours; therefore early diagnosis is critical (Tricoci et al., 2009).

Tajsic et al. (Tajsic et al., 2015) assessed the major shortcoming of cardiac troponin (cTn) due to its incapability to detect an acute coronary syndrome (ACS) in the early hours after symptom onset, due to the delayed increase of its circulating levels after the actual ACS occurrence (so-called "silent Troponin time"). Hence it can't identify (14.2\%) patients had angiographyconfirmed diagnosis of ACS. They concluded that Measurement of hs-cTnl at admission to ED had fairly good diagnostic accuracy for early identification of patients with NSTEMI. However, among patients with initially normal hs-cTnl levels, presenting early after the onset of symptoms (inside $6 \mathrm{~h}$ after symptom onset), there exists promising diagnostic relevance of simultaneous measurement of copeptin levels (dual marker strategy) for a prompt and reliable diagnosis of NSTEMI.

The most important result of this study was found in copeptin since it was high in both UA \& AMI patients with significant differences between men (higher) compared to women on admission but decreased significantly after 6 hrs. in both groups. von Haehling et al. (Von Haehling et al., 2012) found that the predictive performance of copeptin was independent of other clinical variables or cardiovascular risk factors, and superior to that of troponin I or other cardiac biomarkers. They proposed a cutoff value of $21.6 \mathrm{pmol} / \mathrm{L}$ for the composite endpoint after three months (myocardial reinfarction, stroke, all-cause death). The biomarker strategy of a combined copeptintroponin rule-out of AMI has been analyzed in a number of retrospective observational biomarker studies, but this is a study evaluating the safety of early discharge (Mockel et al., 2015).

Copeptin levels were found to be elevated significantly in the first samples (on admission) over the upper limit $(7 \mathrm{pmol} / \mathrm{ml}$.) in the angina groups included in this study on admission, decreased after $6 \mathrm{hrs}$. without exceeding the cut off levels of $14 \mathrm{pmol} / \mathrm{ml}$. Patients developed AMI, copeptin levels were markedly higher in their plasma copeptin levels, exceeding cut off levels on admission \& decreased after $6 \mathrm{hrs}$. which is still over the cut off levels indicating AMI. Although all CPP levels were elevated above the upper limit, their standard deviation was high in both samples either in males or females.
As endogenous stress is present already at the onset of AMI, copeptin appears to be able to identify AMI very early after symptom onset, even when cTn is still negative (Chow et al., 2008; Wu et al., 2009). As the time course of endogenous stress and detectable cardiomyocyte damage seems to be reciprocal, copeptin seems to be the ideal marker to compensate for the sensitivity deficit of conventional cTn assays in early presenters (Reichlin et al., 2009).

Major differences exist in the diagnosis and management of myocardial infarction between men and women presented to ER with suspected ACS. Moreover, using high sensitivity troponin as a single diagnostic marker I proved that it is not efficient in $\mathrm{Ml}$ diagnosis in women and contribute to sex inequalities in treatments and outcomes.

This sex difference has been observed in other studies may be due to differences in presentation, with women more likely to have atypical symptoms and less reliable electrocardiographic changes (Chua et al., 2000). However, others4 have found that the same proportion of men and women reported chest pain and had electrocardiographic changes.

These differences between women and men in ACS may due to vascular biological factors characterized by smaller atheroma burden and slower progression in women, smaller vessel size, less collateral flow, lower coronary flow reserve, more vascular stiffness, differences in remodelling, and functional differences of smooth muscle cells in the vessel wall (White 2001).

Female disparities in vascular flow and structure may cause diagnosis misleading, wrong treatment and increased mortality. ACS in females usually have less extensive obstructive and more diffuse coronary artery disease compared with men, but the event rate in non-obstructive coronary artery disease seems to be higher in women. It was proven that early invasive strategy of patients with unstable angina or non-STEMI ACS reduce mortality in men, but not in women (Hochman et al., 1997).

Many factors influence this gender gap, such as co-morbid conditions at older age, smaller vessel size, more urgent procedures in women and the presence of hypertensive heart disease. Furthermore, after $\mathrm{PCl}$ women have significantly more bleeding complications, especially when glycoprotein Ilb/IIla inhibitors are used (Califf et al., 1989).

Shah et al (Shah et al., 2015) observed the diagnosis of myocardial infarction is twice in men as in women. They also found that use of a high sensitivity troponin assay with sex specific diagnostic thresholds doubles the diagnosis of myocardial infarction in women, become similar to men. They added that women are less than men to be referred to a cardiologist, to undergo 
coronary angiography or revascularisation, or to receive secondary prevention. They had the highest risk of death or recurrent myocardial infarction.

Importantly, although guidelines note that differences exist between the sexes in the reference range for troponin, no explicit recommendations on their use have been made owing to insufficient evidence. Secondary causes of myocardial injury and infarction were more common in women than in men (Maas and Appelman 2010)

Women are at higher short term and long term risk of death after acute coronary syndrome (McQuillan et al., 2014). In our study, women with small undisclosed increases in troponin concentrations that were only discernible using the high sensitivity assay with sex specific diagnostic thresholds, were less likely to receive evidence based treatments and had the highest rates of reinfarction and death at 12 months.

In Conclusion, cardiovascular disease is the major cause of death in women more than in men and is still under-recognized and under treated due to many causes. Differences in presentation of ACS between men and women, with gender-based diagnostic tests, must be respected to improve therapeutic strategies and outcomes in women. Since there is no cardiology guidelines focused on sex-related differences, it has to be considered. Further, women need to be more learnt about their own risk factors and clinical signs of $\mathrm{CHD}$ or ACS since they differ from men.

\section{REFERENCES}

Berger JS, Elliott L, Gallup D, Roe M, Granger CB, Armstrong PW, Simes RJ, White HD, de Werf FV, Topol EJ, Hochman JS, Newby LK, Harrington RA, Califf RM, Becker RC, and Douglas PS. : Sex Differences in Mortality Following Acute Coronary Syndromes. JAMA. 2009 August 26; 302(8): 874-882.

Califf RM, Harrell FE, Lee KL, Rankin S, Hlatky MA, Mark DB, Jones RH, Muhlbaier LH, Oldham HN, Pryor DB. The evolution of medical and surgical therapy for coronary artery disease. A 15-year perspective. JAMA 1989; 261(14):2077-2086.

Chow T, Kereiakes DJ, Onufer J: Does microvolt T-wave alternans testing predict ventricular tachyarrhythmias in patients with ischemic cardiomyopathy and prophylactic defibrillators? The MASTER (Microvolt T Wave Alternans Testing for Risk Stratification of Post-Myocardial Infarction Patients) trial. J Am Coll Cardiol 2008; 52:1607-15.

Chua TP, Saia F, Bhardwaj V, Wright C, Clarke D, Hennessy M, K.M Fox KM. Are there gender differences in patients presenting with unstable angina? International Journal of Cardiology 2000; 72(3):281-286.

Dhakad PK and Sharma PK: Cardiac biomarkers: A boon for diagnosis of acute yocardial infarction patients. Annals of Biological Research 2015; 6 (1): 1-5.

Duchenne J, Mestres S, Dublanchet N, Combaret N, Marceau G, Caumon L, Dutoit L, Ughetto S, Motreff P, Sapin V and Schmidt J.: Diagnostic accuracy of copeptin sensitivity and specificity in patients with suspected non-ST-elevation myocardial infarction with troponin I below the 99th centile at presentation. BMJ 2014, 4: 1 - 9.

Gimenez MR, Wildi $\mathrm{K}$ and Mueller C: What Cardiologists Should Know About Copeptin. Rev Esp Cardiol. 2014;67(7):519-521

Hanson, G. K.: Mechanisms of disease inflammation, Atherosclerosis and coronary artery disease. N. Engl. J. Med., 2005; 352: $1685-1695$.

Hochman JS, McCabe $\mathrm{CH}$, Stone PH. Outcome and profile of women and men presenting with acute coronary syndromes: a report from TIMI IIIB. JACC 1997; 30(1):141-148.

Keller T, Zeller T, Peetz D, Tzikas S, Roth A, Czyz E, Bickel C, Baldus S, Warnholtz A, Frohlich $M$, Sinning CR, Eleftheriadis MS, Wild PS, Schnabel RB, Lubos E, Jachmann N, GenthZotz S, Post F, Nicaud V, Tiret L, Lackner KJ, Munzel TF, Blankenberg S. Sensitive troponin I assay in early diagnosis of acute myocardial infarction.N Engl $J$ Med 2009;361:868-877.

Libby P, Bonow RO, Mann DL, Zipes D, eds. Braunwald's Heart Disease. 8th ed.Philadelphia, Pa: Elsevier Saunders; 2008:1281-1342.

Libby P: Current concepts of the pathogenesis of the acute coronary syndromes. Circulation. 2001;104:365-72.

Liuzzo, G.; Buffon, A.; Biasucci, L. M.; Gallimore, J. R.; Caligiuri, G.; Vitelli, A.; Altamura, S.; Ciliberto, G.; Rebuzzi, A; G.; Crea, F.; Pepys, M. B. and Maseri, A.: Enhanced inflammatory response to coronary angioplasty in patients with severe unstable angina. Circulation 1998; 98: $2370-2376$.

Maas $\mathrm{AH}$ and Appelman YE: Gender differences in coronary heart Disease. Neth Heart J 2010; 18:598-603.

McQuillan BM and Thompson P: Management of acute coronary syndrome in special subgroups: female, older, diabetic and Indigenous patients. MJA - 2014; 201 (10): S91 - S99.

Mockel M, Searle J, Hamm C, Slagman A, Blankenberg S, Huber K, Katus H, Liebetrau C, Muller C, Muller R, Peitsmeyer P, von 
Recum J, Tajsic M, Vollert J, and Giannitsis F.: Early discharge using single cardiac troponin and copeptin testing in patients with suspected acute coronary syndrome (ACS): a randomized, controlled clinical process study. European Heart Journal 2015; 36: 369-376.

Reichlin T, Hochholzer W, Bassetti S, Steuer S, Stelzig C, Hartwiger S, Biedert S,Schaub N, Buerge C, Potocki M, Noveanu M, Breidthardt $\mathrm{T}$, Twerenbold $\mathrm{R}$, Winkler $\mathrm{K}$, Bingisser R, Mueller C. Early diagnosis of myocardial infarction with sensitive cardiac troponin assays. N Engl J Med 2009; 361:858-67.

Reinstadler SJ , Klug G, Feistritzer HJ, Bernhard Metzler B, and JohannesMair J: Copeptin Testing in Acute Myocardial Infarction: Ready for Routine Use?Disease Markers, 2015; $1-10$.

Ridker, P. M. C-Reactive Protein: Eighty Years from Discovery to Emergence as a Major Risk Marker for Cardiovascular Disease. Clinical Chemistry, 2009; 55: 209-215.

Shah AS, Griffiths M, Lee KK, McAllister DA, Hunter AL, Ferry AV, Cruikshank A, Reid A, Stoddart M, Strachan F, Walker S, Collinson PO, Apple FS, Gray AJ, Fox KA, Newby DE, Mills NL. : High sensitivity cardiac troponin and the under-diagnosis of myocardial infarction in women: prospective cohort study. BMJ 2015;350:g7873

Tajsic M, Jarai R, Schwarz MA, Kitzbrecht J, Koch $\mathrm{J}$, Wojta $\mathrm{J}$ and Huber $\mathrm{K}$ : Copeptin as a part of the dual biomarker strategy for early diagnosis of non ST segment elevation myocardial infarction WILCOP study. ECC congress 2015; P436-74 Infarction acute phase non STEMI.

Tricoci P, Allen JM, Kramer JM, Califf RM, Smith SC Jr.: Scientific evidence underlying the ACC/AHA clinical practice guidelines. JAMA 2009; 301: 831- 41.

Vaccarino V, Rathore SS, Wenger NK, Frederick PD, Abramson JL, Barron HV, Manhapra A, Mallik S, and Krumholz HM. Sex and Racial Differences in the Management of Acute Myocardial Infarction, 1994 through 2002.N Engl J Med. 2005 August 18; 353(7): 671682.

Von Haehling S, Papassotiriou J, Morgenthaler NG, Hartmann O, Doehner W, Stellos K, Wurster T, Schuster A, Nagel E, Gawaz M, Bigalke B: Copeptin as a prognostic factor for major adverse cardiovascular events in patients with coronary artery disease. Int $\mathrm{J}$ Cardiol 2012; 162: 27-32.

Walter V, Magnin J, Goy J, Garcia W, Hayoz D, Ribordy V, Allemann $Y$ and Cook S.: Copeptin for early diagnosis of myocardial infarction. CARDIOVASCULAR MEDICINE 2015; 18(9):252-257

White $H$. Hirulog and Early Reperfusion or Occlusion -2 Trial I. Lancet 2001; 358(9296):1855-1863.

Wu AH, Agee SJ, Lu QA, Todd J, Jaffe AS. : Specificity of a high-sensitivity cardiac troponin I assay using single-molecule counting technology. Clin Chem 2009; 55:196-8. 